\title{
Isolation of fungal pathogens from eggs of the endangered sea turtle species Chelonia mydas in Ascension Island
}

\author{
JULLIE M. SARMIENTO-RAMIREZ', ${ }^{1}$, JOLENE SIM ${ }^{2}$, PIETER VAN WEST ${ }^{3}$ \\ AND JAVIER DIEGUEZ-URIBEONDO ${ }^{1}$ \\ ${ }^{1}$ Departamento de Micología, Real Jardín Botánico-CSIC, Plaza Murillo 2, 28014, Madrid, Spain, ${ }^{2}$ Ascension Island Government, \\ Ascension Island, South Atlantic Ocean, ASCN 1ZZ, ${ }^{3}$ Aberdeen Oomycete Laboratory, College of Life Sciences and Medicine, \\ University of Aberdeen, Foresterhill AB25 2ZD, Scotland, UK
}

\begin{abstract}
Fungal emerging pathogens are one of the main threats for global biodiversity. Sea turtles do not seem to be an exemption, and recent studies on important nesting areas worldwide have shown that two fungal pathogens, i.e. Fusarium falciforme and Fusarium keratoplasticum, are involved in low hatching success in nests of sea turtle species. Although the presence of these pathogens has been detected in Ascension Island, there are no investigations on the distribution of these two pathogens in main nesting beaches in the island. In this study, we analysed 109 eggshells of the species Chelonia mydas from four nesting areas in Ascension Island. We have isolated and identified a total of 46 fungal isolates. A phylogenetic analysis, of the ITS nrDNA region, with a number of reference sequences of the Fusarium solani species complex, showed that 23 of these isolates corresponded to the pathogen F. keratoplasticum. The analyses on isolation frequency, that included other previously obtained isolates, i.e. $11 \mathrm{~F}$. keratoplasticum and one F. falciforme, showed that F. keratoplasticum was the species most frequently isolated in Ascension Island and it was found in all nesting beaches, while F. falciforme was only isolated from Pan Am beach. When compared with other nesting areas worldwide, the abundance of $\mathrm{F}$. keratoplasticum over $\mathrm{F}$. falciforme was higher than any other nesting region tested. These findings are important in order to evaluate the potential threat of this pathogen to nests of the sea turtle population of Ascension Island, and to develop future control strategies.
\end{abstract}

Keywords: Distribution, fungal pathogens, sea turtle eggs, nesting areas, conservation

Submitted 1 August 2014; accepted 22 September 2016; first published online 5 December 2016

\section{INTRDDUCTION}

Emerging pathogens are affecting a wide number of species worldwide, representing an important negative factor in the current global biodiversity crisis (Daszak et al., 1999, 2000). In the marine ecosystem, the occurrence and severity of diseases have dramatically increased during the last 20 years mainly due to emerging pathogens and global climate change (Altizer et al., 2003; Harvell et al., 2009). Studies to identify the pathogens responsible for these diseases, combined with information on environmental drivers have helped to better understand these diseases. For example, aspergillosis is a fungal emerging disease in corals, mainly caused by Aspergillus sidowii, and it has produced massive mortalities in Caribbean populations. Recent studies on diseased coral species in the Tropical Eastern Pacific (TEP) have revealed that $A$. sidowii is the most frequently isolated species and it might be implicated in mortalities in TEP coral populations (Barrero-Canosa et al., 2013).

In sea turtles, the pathogens F. keratoplasticum and F. falciforme cause a potentially lethal disease (Sarmiento-Ramírez et al., 2010, 2014a). These species possess a number of

Corresponding author:

J. Dieguez-Uribeondo

Email: dieguez@rib.csic.es biological features that are similar to those of known fungal pathogens involved in emerging infectious diseases and host extinctions, which impose an enormous threat for all sea turtle species (Sarmiento-Ramírez et al., 2014a). These pathogenic species seem to have a global distribution and are present in the main nesting areas for at least six of the seven existing sea turtle species, including Ascension Island. Ascension Island hosts one of the most important and well protected nesting populations of green sea turtles (Chelonia mydas) in the world (Broderick et al., 2006; Weber et al., 2014). Thus, it is very important to identify the presence of fungal pathogens such as F. keratoplasticum and F. falciforme and therefore assess the threat that these pathogens might represent to the nesting population at Ascension Island.

In order to understand the threat that F. keratoplasticum and $F$. falciforme represent for sea turtle populations it is also key to detect environmental drivers of Fusarium disease. In eggs, this disease seems to be highly dependent on environmental factors (Sarmiento-Ramirez et al., 2014a). However, there are no investigations of the potential source of these pathogens in nesting beaches. The species F. keratoplasticum and F. falciforme belong to the Fusarium solani species complex (FSSC), and are some of the most clinically important pathogens (Short et al., 2011, 2013). Studies on the distribution and source of these pathogens have revealed that a large majority of isolates of F. keratoplasticum are 
present worldwide, mostly from indoor aquatic biofilms and infections of animals (Zhang et al., 2006; Mehl \& Epstein, 2008; Short et al., 2011). Moreover this species is mainly isolated from environments significantly impacted by human activity (Short et al., 2013). Regarding F. falciforme, it is a pathogen rarely found to cause animal diseases in tropical areas and it is not a common fungus of food, household plant material, garden soil or domestic water, as $F$. solani is (Summerbell \& Schroers, 2002). However, the main source of infection for $F$. falciforme seems to be the soil and plant debris particles (Zhang et al., 2006). In this study we will also discuss the potential source of $F$. keratoplasticum and $F$. falciforme in nesting beaches at Ascension Island.

To sum up, in order to understand the potential threat that $F$. keratoplasticum and F. falciforme represent for the green sea turtle nesting population nesting at Ascension Island, it is key to understand the distribution of these species in the nesting locations and the source of infection. With this purpose, we carried out fungal isolations and molecular characterization of the isolates from egg shells of the sea turtle species $C$. mydas collected at Ascension Island.

\section{MATERIALS AND METHDDS}

\section{Fungal isolations and molecular characterization}

A total of 109 egg shells, of the green sea turtle, showing symptoms of fungal infection, i.e. egg shells that exhibited unusual coloured spots (yellow, blue, greyish) (Sarmiento-Ramírez et al., 2010), were collected from sea turtle nests laid at English bay (29), North East bay (30), Pan Am beach (15) and Long beach (35) at Ascension Island (Figure 1). All samples were taken after the nest emergence. Fungi were isolated by placing fragments of the egg shells on peptone glucose agar (PGA) with ampicillin $\left(100 \mathrm{mg} \mathrm{l}^{-1}\right)$. Pure cultures are kept in the culture collection of the Real Jardín Botánico-CSIC, Madrid, Spain.

For molecular characterization, DNA was extracted from pure cultures using the DNA Easy PlantMini Kit (Qiagen, Valencia, CA). DNA fragments containing internal transcribed spacers ITS 1 and ITS 2 including $5.8 \mathrm{~S}$ were amplified and sequenced with primer pair $\mathrm{ITS}_{5} / \mathrm{ITS}_{4}$ (White et al., 1990). Amplification of the ITS nrDNA was carried out with the Ready-to-Go-PCR Beads (GE Healthcare Life Sciences, Buckinghamshire, UK). The amplification program was initial denaturalization at $94^{\circ} \mathrm{C}$ for $5 \mathrm{~min} ; 5$ cycles of $94^{\circ} \mathrm{C}$ for $30 \mathrm{~s}, 54^{\circ} \mathrm{C}$ for $30 \mathrm{~s}$ and $72^{\circ} \mathrm{C}$ for $1 \mathrm{~min}$; followed by 33 cycles of $94^{\circ} \mathrm{C}$ for $30 \mathrm{~s}, 48^{\circ} \mathrm{C}$ for $30 \mathrm{~s}$ and $72^{\circ} \mathrm{C}$ for $1 \mathrm{~min}$; with a final extension at $72^{\circ} \mathrm{C}$ for 10 min (Martin \& Winka, 2000). The amplification products were purified using QIAquick gel extraction kit (QIAGEN, Hilden, Germany) and sequenced by MACROGEN (Inc. Seoul, Korea). Sequencher 4.2 (Gene Codes Corporation, Ann Arbor, MI) was used to identify the consensus sequence from the two strands of the ITS nrDNA of each isolate. For initial identification of the isolates, the ITS nrDNA sequences were compared with those of the National Center of Biotechnology Information (NCBI) nucleotide databases using the Nucleotide BLASTN tool.

\section{Phylogenetic analyses}

For precise identification of the Fusarium spp. phylogenetic analyses, including the isolates initially identified as members of the F. solani species complex (FSSC), were carried out. The generated ITS nrDNA sequences from isolated Fusarium (Table 1), 146 NCBI-GenBank sequences of Fusarium turtle egg isolates from previous studies from Ecuador (44) and Cape Verde (68), and 6o selected sequences of Fusarium spp. from other hosts and environments were included (Sarmiento-Ramirez et al., 2014a, b). The program Se-Al 2.0a11 Carbon (Rambaut, 2002) was used for manual alignment of the sequences. Maximum parsimony (MP) (Swofford, 2003) was inferred using the heuristic search option in PAUP* 4.ob10. The bootstrap proportion was used to assess confidence for a specific node (Felsenstein, 1985; Lutzoni et al., 2004). Phylogenetic trees were edited with TreeView (Page, 1996). Newly obtained sequences of the $F$. falciforme and F. keratoplasticum isolates were submitted to GenBank with accession numbers KJ944397 through KJ944419.

\section{Differences in isolation of $F$. keratoplasticum and $F$. falciforme in nesting areas in Ascension Island}

In order to analyse the differences in distribution of F. keratoplasticum and F. falciforme and other fungi between nesting areas, the isolation frequency of these fungi was calculated. The isolation frequency of these species and other fungi in the Island was calculated as the number of isolates of each species over the number of overall fungal isolates. The isolation frequency of each species per nesting area was also calculated. The analyses also included isolates of $F$. keratoplasticum (11) and F. falciforme (1), obtained in a previous study (Sarmiento-Ramirez et al., 2014a).

\section{RESULTS}

\section{Fungal isolations}

A total of 46 fungal isolates were obtained from 109 eggshells (Table 1). A total of 23 of these isolates were initially identified as members of the FSSC, based on the NCBI BLAST analysis of the ITS nrDNA sequences (Table 1). Phylogenetic MP and Bayesian analyses showed that these isolates belonged to the species F. keratoplasticum (Table 1 and Figure 2). The other 21 fungal isolates were identified as members of the genera Fusarium (2), Pseudallescheria (10), Scedosporium (1), Aspergillus (3), Phoma (2), Alternaria (1), Gymnascella (1) and Pleosporales (1). The genera of other two fungal isolates were undetermined (Table 1$)$.

\section{Differences in isolation of $F$. keratoplasticum and $F$. falciforme in nesting areas in Ascension Island}

The analyses included all the fungal isolates obtained, to date, from sea turtle eggs at Ascension Island, i.e. a total of 34 F. keratoplasticum isolates, one F. falciforme and 23 fungal isolates from other genera. These analyses showed that 58\% (34 out 
A

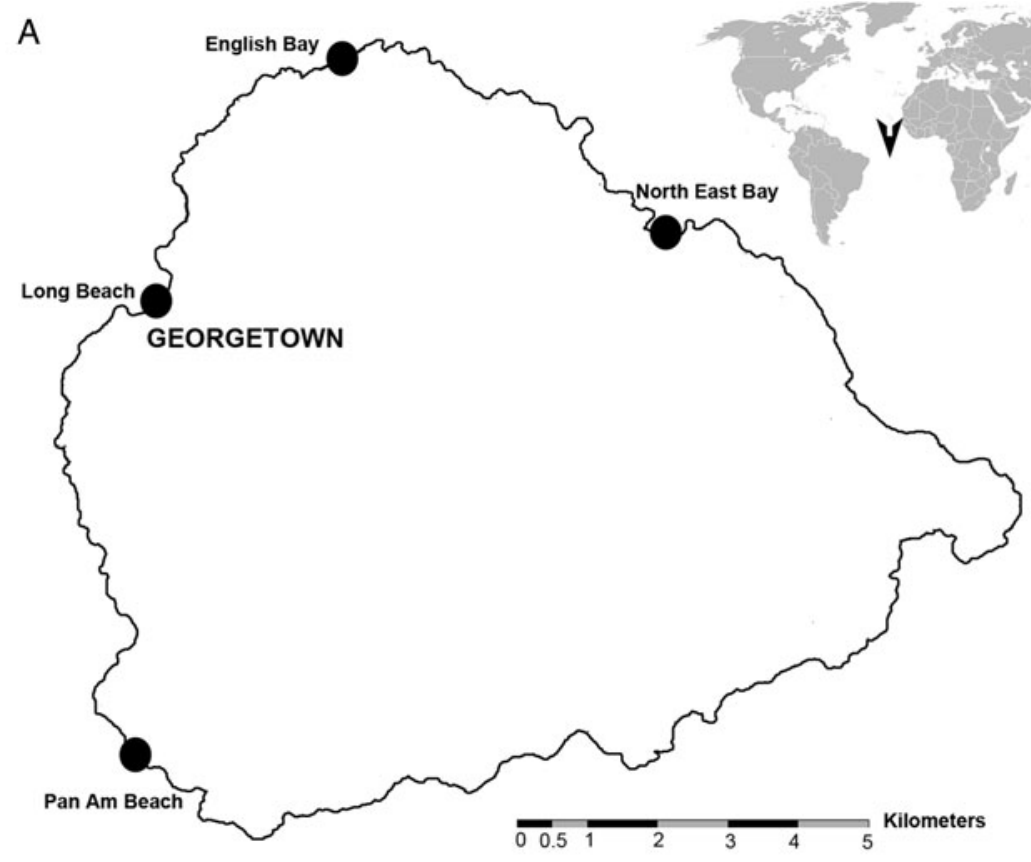

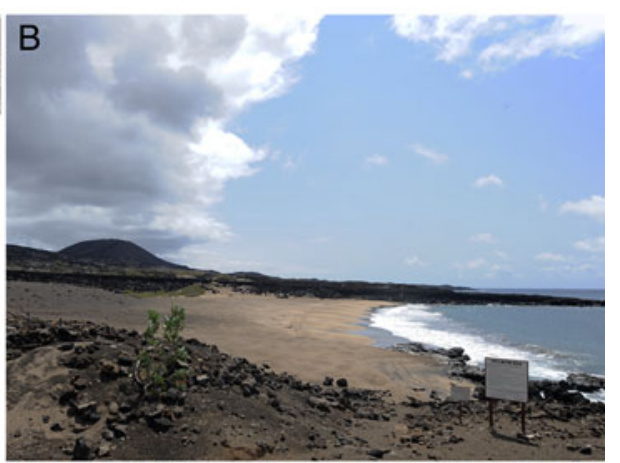

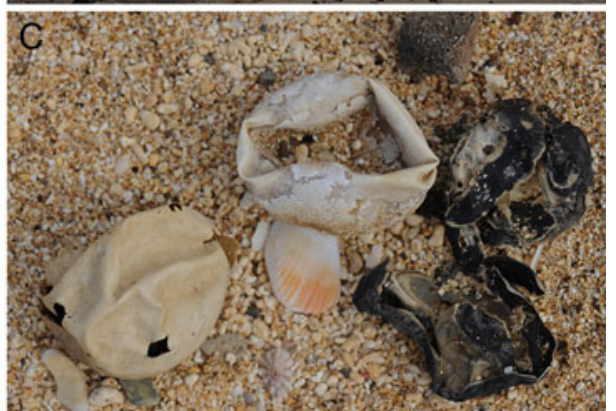

Fig. 1. Sea turtle nesting areas sampled for isolation and characterization of Fusarium species at Ascension Island: (A) Nesting areas sampled at Ascension Island; (B) North East Bay; (C) egg shells with symptoms of Fusarium disease and dead embryos found in the sampled nests (Long Beach).

of 58 ) of the isolates belonged to the species F. keratoplasticum, $40 \%$ (23 out of 58 ) belonged to other fungi, and the species F. falciforme represented $2 \%$ (1 out of 58 ) of the isolates (Table 1 and Figure 3).

The species F. keratoplasticum was isolated from all locations sampled and F. falciforme was only isolated from Pan Am Beach (Table 1). 47\% (16 out of 34) of F. keratoplasticum isolates was obtained from Long beach, $23 \%$ (8 out of 34 ) from North East Bay, 15\% (5 out of 34) from Pan Am Beach, 9\% from English Bay and 6\% from an undetermined nesting area (Table 1).

\section{DISCUSSIDN}

In this study, we found that the pathogenic species Fusarium keratoplasticum is the Fusarium spp. most frequently isolated from egg shells of the green sea turtle species nesting at Ascension Island. The phylogenetic analyses of ITS nrDNA region demonstrated that the majority, i.e. $97 \%$ (34 out of 35) of the Fusarium isolates that belong to the Fusarium solani species complex obtained from sea turtle egg shells at Ascension Island, corresponded to the species F. keratoplasticum and only one isolate corresponded to the species F. falciforme. A previous study on the global distribution of the sea turtle egg pathogens $F$. keratoplasticum and F. falciforme showed that these pathogens are distributed in major sea turtle nesting regions including Ascension Island (Sarmiento-Ramírez et al., 2014a). However, this is the first time that differences in distribution of both Fusarium spp. are described among nesting locations in Ascension Island.

The analyses on distribution of the Fusarium spp. on Ascension Island showed that F. keratoplasticum is present in all locations sampled and this species was most frequently isolated from Long Beach (16 out of 34). Fusarium keratoplasticum is mainly isolated from environments significantly impacted by human influence (Short et al., 2013). Interestingly, Long Beach is located near to Georgetown, the largest settlement on the Island, which might play a role in the high presence of F. keratoplasticum. This beach also has by far the greatest density of nests in the island, which can influence the presence of this pathogenic fungus. Regarding F. falciforme, it was only found at Pan Am Beach, which is not subject to a large amount of human activity. Indeed, F. falciforme is usually not a common fungus in areas impacted by humans (Summerbell \& Schroers, 2002). The presence of $F$. falciforme in this beach might be influenced by the major presence of plant debris compared with other nesting beaches in the island. Further studies on the source of both Fusarium spp. should be addressed in order to reduce the potential impact of these species on nesting areas of Ascension Island.

If compared with other nesting areas worldwide, the isolation frequency of the pathogenic species $F$. keratoplasticum (97\%) over F. falciforme (3\%) is higher than any other nesting region tested, i.e. Cape Verde and Ecuador, where the isolation frequency of $F$. keratoplasticum over F. falciforme is 75 and $23 \%$ respectively (Sarmiento-Ramirez et al., 2014a, b). These data might suggest a prevalence of the species F. keratoplasticum over F. falciforme in nesting areas located in the Atlantic (Ascension Island and Cape Verde) compared with those located in the Pacific (Ecuador). Although F. keratoplasticum is known to cause diseases worldwide (Short et al., 2013), this is the first time that this species is described as the most represented Fusarium spp. on the sea nesting regions located in the Atlantic Ocean. Although F. falciforme is considered a serious pathogen, it is rarely found causing disease in tropical and subtropical areas (Guarro et al., 1997); this study demonstrates that this fungal species has a broader distribution and is most frequent in tropical areas. Certainly, in recent years, there has been evidence that $F$. 
Table 1. Fungal isolates found in eggshells of the sea turtle species Chelonia mydas in Ascension Island.

\begin{tabular}{|c|c|c|c|c|}
\hline Line number & Strain $^{a}$ & Species & GenBank accession $^{\mathbf{b} *}$ & Location $^{c}$ \\
\hline 1 & 223 FUS & F. keratoplasticum & $\mathrm{KC}_{574007^{*}}$ & North East Bay \\
\hline 2 & 227 FUS & F. keratoplasticum & $\mathrm{KC}_{574008^{*}}$ & Long Beach \\
\hline 3 & 228 FUS & F. keratoplasticum & KC574009* & Undetermined \\
\hline 4 & 230 FUS & F. keratoplasticum & $\mathrm{KC}_{574010^{*}}$ & Undetermined \\
\hline 5 & 233 FUS & F. keratoplasticum & $\mathrm{KC}_{574011^{*}}$ & Pan Am Beach \\
\hline 6 & 235 FUS & F. keratoplasticum & $\mathrm{KC}_{574013^{*}}$ & Pan Am Beach \\
\hline 7 & 236 FUS & F. keratoplasticum & $\mathrm{KC}_{574014^{*}}$ & Pan Am Beach \\
\hline 8 & 237 FUS & F. keratoplasticum & $\mathrm{KC}_{574015^{*}}$ & Pan Am Beach \\
\hline 9 & 238 FUS & F. keratoplasticum & $\mathrm{KC}_{574016^{*}}$ & Long Beach \\
\hline 10 & 239 FUS & F. keratoplasticum & $\mathrm{KC}_{574017^{*}}$ & Long Beach \\
\hline 11 & 240 FUS & F. keratoplasticum & $\mathrm{KC}_{574018^{*}}$ & Long Beach \\
\hline 12 & 241 FUS & F. keratoplasticum & KJ944397 & Long Beach \\
\hline 13 & 242 FUS & F. keratoplasticum & KJ944398 & Long Beach \\
\hline 14 & 243 FUS & F. keratoplasticum & KJ944399 & Long Beach \\
\hline 15 & 244 FUS & F. keratoplasticum & KJ944400 & Long Beach \\
\hline 16 & 245 FUS & F. keratoplasticum & KJ944401 & Long Beach \\
\hline 17 & 246 FUS & F. keratoplasticum & KJ944402 & Long Beach \\
\hline 18 & 247 FUS & F. keratoplasticum & KJ944403 & Long Beach \\
\hline 19 & 248 FUS & F. keratoplasticum & KJ944404 & Long Beach \\
\hline 20 & 249 FUS & F. keratoplasticum & KJ944405 & Long Beach \\
\hline 21 & 250 FUS & F. keratoplasticum & KJ944406 & Long Beach \\
\hline 22 & 251 FUS & F. keratoplasticum & KJ944407 & Long Beach \\
\hline 23 & 252 FUS & F. keratoplasticum & KJ944408 & English Bay \\
\hline 24 & 253 FUS & F. keratoplasticum & KJ944409 & English Bay \\
\hline 25 & 255 FUS & F. keratoplasticum & KJ944410 & English Bay \\
\hline 26 & 259 FUS & F. keratoplasticum & KJ944411 & North East Bay \\
\hline 27 & 261 FUS & F. keratoplasticum & KJ944412 & North East Bay \\
\hline 28 & 263 FUS & F. keratoplasticum & KJ944413 & North East Bay \\
\hline 29 & 265 FUS & F. keratoplasticum & KJ944414 & North East Bay \\
\hline 30 & 266 FUS & F. keratoplasticum & KJ944415 & North East Bay \\
\hline 31 & 268 FUS & F. keratoplasticum & KJ944416 & North East Bay \\
\hline 32 & 270 FUS & F. keratoplasticum & KJ944417 & North East Bay \\
\hline 33 & 298 FUS & F. keratoplasticum & KJ944418 & Long Beach \\
\hline 34 & 300 FUS & F. keratoplasticum & KJ944419 & Pan Am Beach \\
\hline 35 & 234 FUS & F. falciforme & $\mathrm{KC}_{574012^{*}}$ & Pan Am Beach \\
\hline 36 & 269 FUS & F. equiseti & & North East Bay \\
\hline 37 & 257 FUS & F. chlamydosporum & & English Bay \\
\hline 38 & 256 FUS & Pseudallescheria boydii & & English Bay \\
\hline 39 & 258 FUS & Pseudallescheria boydii & & English Bay \\
\hline 40 & 262 FUS & Pseudallescheria boydii & & North East Bay \\
\hline 41 & 264 FUS & Pseudallescheria boydii & & North East Bay \\
\hline 42 & 301 FUS & Pseudallescheria boydii & & English Bay \\
\hline 43 & 302 FUS & Pseudallescheria boydii & & English Bay \\
\hline 44 & 304 FUS & Pseudallescheria boydii & & North East Bay \\
\hline 45 & 305 FUS & Pseudallescheria boydii & & North East Bay \\
\hline 46 & 306 FUS & Pseudallescheria boydii & & North East Bay \\
\hline 47 & 308 FUS & Pseudallescheria boydii & & North East Bay \\
\hline 48 & 297 FUS & Scedosporium aurantiacum & & Long Beach \\
\hline 49 & 225 FUS & Aspergillus tamarii & & Undetermined \\
\hline 50 & 299 FUS & Aspergillus sclerotiorum & & Long Beach \\
\hline 51 & 307 FUS & Aspergillus sp. & & North East Bay \\
\hline 52 & 226 FUS & Phoma multirostrata & & Long Beach \\
\hline 53 & 267 FUS & Phoma sp. & & North East Bay \\
\hline 54 & 232 FUS & Alternaria sp & & Undetermined \\
\hline 55 & 224 FUS & Gymnascella hyalinospora & & Undetermined \\
\hline 56 & 254 FUS & Pleosporales & & English Bay \\
\hline 57 & 229 FUS & Undetermined & & Undetermined \\
\hline 58 & 231 FUS & Undetermined & & Undetermined \\
\hline
\end{tabular}

${ }^{\text {a }}$ Code of the fungal isolates deposited in the fungal collection of the Real Jardín Botánico-CSIC.

${ }^{\mathbf{b}}$ GenBank accession number of the fungal isolates. The asterisks indicate the isolates obtained in a previous work (Sarmiento-Ramírez et al., 2014a).

${ }^{c}$ Location undetermined means that it was not possible to track the origin of the samples from which those fungi were obtained. 


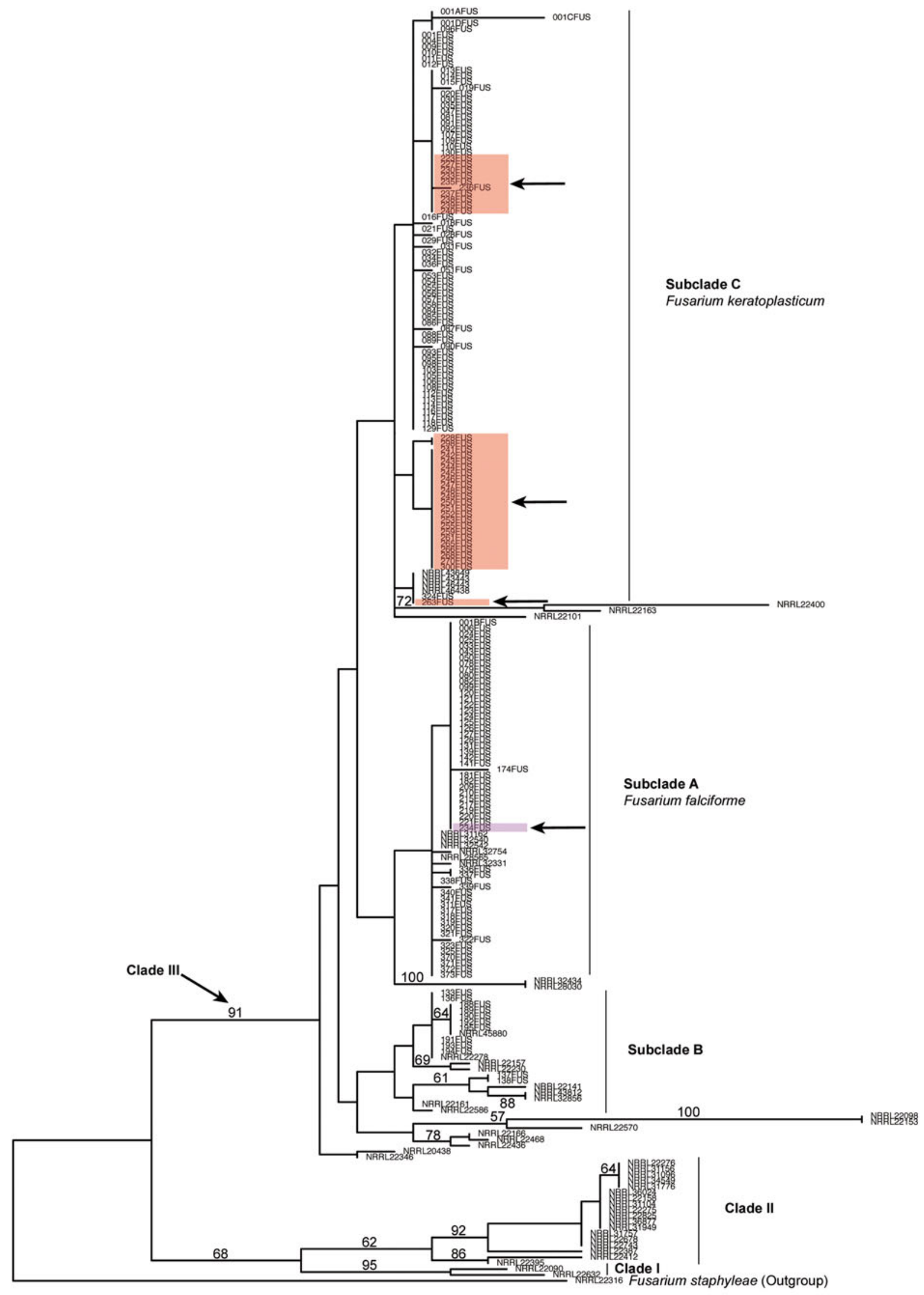

-0.5 changes

Fig. 2. Out-group rooted cladogram of the ITS nrDNA region of isolates within the Fusarium solani species complex (FSSC). One of the most parsimonious trees inferred from the ITS nrDNA sequence data of 146 sea turtle fungal isolates and 60 non-sea turtle fungal isolates. The numbers on the internodes indicate the bootstrap values (BS) of the parsimony analysis. Highlighted isolates correspond to those obtained from sea turtle egg shells collected at Ascension Island $(\mathrm{N}=35)$. 


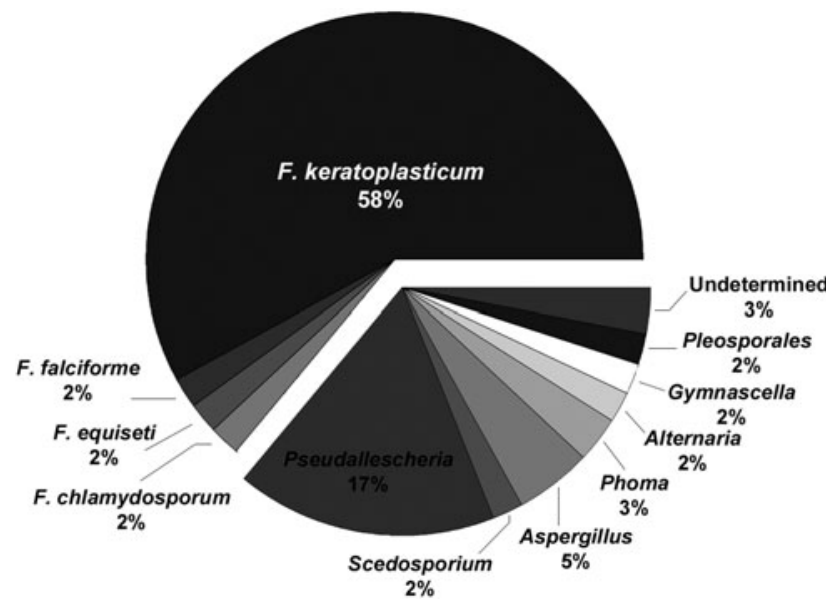

Fig. 3. Pie chart showing the isolation frequency of the fungal isolates found in eggshells of the sea turtle species Chelonia mydas from several nesting areas at Ascension Island.

falciforme is emerging as an agent of infections (Van Etta et al., 1983; Miró et al., 1994; Lau et al., 1995; Noble et al., 1997), thus overlapping more broadly in pathogenic potential with Fusarium solani. Fusarium ketatoplasticum and F. falciforme are capable of causing disease on sea turtle eggs and further studies on prevalence of both species and the potential impact of this prevalence on nesting populations are necessary.

Fungi are highly sensitive to environmental conditions and especially to changes in weather and climate, in particular temperature, humidity and wind that can directly influence their growth, spread and survival (Harvell et al., 2002). Thus, the potential prevalence of $F$. keratoplasticum in Atlantic nesting areas and F. falciforme in those located in the Pacific might respond to the microclimatic conditions that they share. However, climate change seems to influence dispersion of fungal pathogens mainly as a consequence of current global warming (García-Solache \& Casadevall, 2010). Thus, under current climate change scenarios, sea turtles could be threatened because these conditions might favour the dispersion and development of the Fusarium disease caused by $F$. keratoplasticum and F. falciforme. Further studies on environmental conditions responsible for prevalence of both species on sea turtle nesting areas and the implications of this prevalence to sea turtle conservation should be addressed.

To sum up, F. keratoplasticum seems to be the main pathogenic species present on sea turtle eggs in Ascension Island and in nesting regions located in the Atlantic. Moreover, $F$. falciforme is rarely found in the Atlantic and seems to be most dominant in nesting areas of the Pacific. Further studies on the source of these species and prevalence should be carried out to establish strategies directed at controlling these pathogens and their pathogenic effect on sea turtles.

\section{FINANCIAL SUPPDRT}

This work was supported by grants of Ministerio de Ciencia e Innovación, Spain (CGL2009-10032, CGL2012-32934), J.M.S.R. was supported by $\mathrm{PhD}$ fellowship of the CSIC
(JAEPre 0901804). P.v.W. was supported by the University of Aberdeen and a Darwin award to Dr Paul Brickle.

\section{REFERENCES}

Altizer S., Harvell D. and Friedle E. (2003) Rapid evolutionary dynamics and disease threats to biodiversity. Trends in Ecology and Evolution 18, 589-596.

Barrero-Canosa J., Dueñas L.F. and Sanchez J.A. (2013) Isolation of potential fungal pathogens in gorgonian corals at the Tropical Eastern Pacific. Coral Reefs 32, 35-41.

Broderick A.C., Frauenstein R., Glen F., Hays G.C., Jackson A.L., Pelembe T., Ruxton G.D. and Godley D.J. (2006) Are green turtles globally endangered? Global Ecology and Biogeography 15, 21-26.

Daszak P., Berger L., Cunningham A.A., Hyatt A.D., Green D.E. and Speare R. (1999) Emerging infectious diseases and amphibian population declines. Emerging Infectious Diseases 5, 735-748.

Daszak P., Cunningham A.A. and Hyatt A.D. (2000) Emerging infectious diseases of wildlife - threats to biodiversity and human health. Science 287, 443-449.

Felsenstein J. (1985) Confidence limits on phylogenies: an approach using the bootstrap. Evolution 39, 783-791.

Guarro J., Gams W., Pujol I. and Gene J. (1997) Acremonium species: new emerging fungal opportunists in vitro antifungal susceptibilities and review. Clinical Infectious Diseases 25, 1222-1229.

Harvell C.D., Mitchell C.E., Ward J.R., Altizer S., Dobson A.P., Ostfeld R.S. and Samuel M.D. (2002) Climate warming and disease risks for terrestrial and marine biota. Science 296, 2158-2162.

Harvell D., Altizer S., Cattadori I.M., Harrington L. and Weil E. (2009) Climate change and wildlife diseases: when does the host matter the most? Ecology 90, 912-920.

Garcia-Solache M.A. and Casadevall A. (2010) Global warming will bring new fungal diseases for mammals. mBio 1, 1-3.

Lau Y.L., Yuen K.Y., Lee C.W. and Chan C.F. (1995) Invasive Acremonium falciforme infection in a patient with severe combined immunodeficiency. Clinical Infectious Diseases 20, 197-198.

Lutzoni F., Kauff F., Cymon J.C., McLaughlin D., Celio G., Dentinger B., Padamsee M., Hibbett D., James T.Y., Baloch E., Grube M., Reeb V., Hofstetter V., Schoch C., Arnold E., Miadlikowska J., Spatafora J., Johnson D., Hambleton S., Crockett M., Shoemaker R., Sung G.-H., Lücking R., Lumbsch T., O’Donnell K., Binder M., Diederich P., Ertz D., Gueidan C., Hansen K., Harris R.C., Hosaka K., Young-Woon L., Randon M., Nishida H., Pfister D., Rogers J., Rossman A., Schmitt I., Sipman H., Stone J., Sugiyama J., Yahr R. and Vilgalys R. (2004) Assembling the fungal tree of life: progress, classification, and evolution of subcellular traits. American Journal of Botany 91, 1446-1480.

Martin M.P. and Winka K. (2000) Alternative methods of extracting and amplifying DNA from lichens. Lichenologist 32, 189-196.

Mehl H.L. and Epstein L. (2008) Sewage and community shower drain are environmental reservoirs of Fusarium solani species complex group 1, a human and plant pathogen. Environmental Microbiology $1,219-227$

Miro O., Ferrando J., Lecha V. and Campistol J.M. (1994) Abscesos subcutaneos por Acremonium falciforme en un trasplantado renal. Medicina Clinica (Barcelona) 102, 316.

Noble R.C., Salgado J., Newell S.W. and Goodman N.L. (1997) Endophthalmitis and lumbar diskitis due to Acremonium falciforme in a splenectomized patient. Clinical Infectious Diseases 24, 277-278. 
Page R.D.M. (1996) TreeView: an application to display phylogenetic trees on personal computers. Computer Applications in the Biosciences 12, 357-358.

Rambaut A. (2002) Se-Al sequence alignment editor. Oxford: University of Oxford. Available: http://tree.bio.ed.ac.uk/software/seal/.

Sarmiento-Ramírez J.M., Abella E., Martín M.P., Tellería M.T., López-Jurado L.F., Marco A. and Diéguez-Uribeondo J. (2010) Fusarium solani is responsible for mass mortalities in nests of loggerhead sea turtle, Caretta caretta, in Boavista, Cape Verde. FEMS Microbiology Letters 312, 192-200.

Sarmiento-Ramírez J.M., Abella E., Phillott A.D., Sim J., Martín M.P., Marco A. and Diéguez-Uribeondo J. (2014a) Global distribution of two fungal pathogens threatening endangered sea turtles. PLoS ONE 9, $\mathrm{e} 85853$.

Sarmieto-Ramírez J.M., van der Voort M., Raaijmakers J.M. and Dieguez-Uribeondo J. (2014b) Unravelling the microbiome of eggs of the endangered sea turtle Eretmochelys imbricata identifies bacteria with activity against the emerging pathogen Fusarium falciforme. PLoS ONE 9, e95206

Short D.P.G., O'Donnell K., Thrane U., Nielsen K.F., Zhang N., Juba J.H. and Geiser D.M. (2013) Phylogenetic relationships among members of the Fusarium solani species complex in human infections and the descriptions of F. keratoplasticum sp. nov. and F. petroliphilum stat. nov. Fungal Genetics and Biology 53, 59-70.

Short D.P.G., O’Donnell K., Zhang N., Juba J.H. and Geiser D.M. (2011) Widespread occurrence of diverse human pathogenic types of the fungus Fusarium detected in plumbing drains. Journal of Clinical Microbiology 49, 4264-4272.

Summerbell R.C. and Schroers H.J. (2002) Analysis of phylogenetic relationship of Cylindrocarpon lichenicola and Acremonium falciforme to the Fusarium solani species complex and a review of similarities in the spectrum of opportunistic infections caused by these fungi. Journal of Clinical Microbiology 40, 2866-2875.

Swofford D.L. (2003) PAUP*: phylogenetic analysis using parsimony ( ${ }^{*}$ and other methods). Sunderland, MA: Sinauer Associates.

Van Etta L. L., Peterson L. R. and Gerding D. N. (1983) Acremonium falciforme (Cephalosporium falciforme) mycetoma in a renal transplant patient. Archives of Dermatology 119, 707-708.

Weber S.B., Weber N., Ellick J., Avery A., Frauenstein R., Godley B.J., Sim J., Williams N. and Broderick A.C. (2014) Recovery of the South Atlantic's largest green turtle nesting population. Biodiversity and Conservation 23, 3005-3018. doi: 10.1007/s10531-014-0759-6.

White T.J., Bruns T., Lee S. and Taylor J.W. (1990) Amplification and direct sequencing of fungal ribosomal RNA genes for phylogenetics. In Innis M.A., Gelfand D.H., Sninsky J.J. and White T.J. (eds) PCR protocols: a guide to methods and applications. Orlando, FL: Academic Press, pp. 315-322.

and

Zhang N., O’Donnell K., Deanna A.S., Ameena F.N., Summerbell R.C., Arvind A.P. and Geiser D.M. (2006) Members of the Fusarium solani species complex that cause infections in both humans and plants are common in the environment. Journal of Clinical Microbiology 44, 2186-2190.

\section{Correspondence should be addressed to:}

J. Dieguez-Uribeondo

Departamento de Micología, Real Jardín Botánico-CSIC, Plaza Murillo 2, 28014, Madrid, Spain email: dieguez@rjb.csic.es 